\title{
STUDI PENGARUH SIGNAGE TERHADAP ESTETIKA VISUAL KORIDOR JALAN AHMAD YANI MEDAN DITINJAU DARI ASPEK HARMONI DAN KONTRAS
}

\author{
Ryan Muharram ${ }^{(1)}$, Raimundus Pakpahan, ST. MT ${ }^{(2)}$, Putri P. Napitupulu, ST.MT ${ }^{(3)}$ \\ (1) Mahasiswa, Prodi Arsitektur, Fakultas Teknik, Universitas Katolik Santo Thomas Sumatera Utara \\ (2) Staff Pengajar, Prodi Arsitektur, Fakultas Teknik, Universitas Katolik Santo Thomas Sumatera Utara \\ Email :pakpahanray@yahoo.co.id \\ (3) Staff Pengajar, Prodi Arsitektur, Fakultas Teknik, Universitas Katolik Santo Thomas Sumatera Utara \\ Email :putriN70@gmail.com
}

\begin{abstract}
Signage is one of the constituent elements of the city; there are so many types of signage, this study is limited to one type of signage only which is billboards. The diversity of existing billboards will be interesting when properly planned if the presence of billboards are not set properly and by its function than it is not impossible that the expected atmosphere can turn into an unpleasant atmosphere and damage the value of visual aesthetics. In the aesthetics there are harmony and contrast; as is a theory that supports the success of the design of public space regarding aesthetics is good to avoid the monotony and has a quality appeal. The research problem is how the billboards influence visual aesthetics on Ahmad Yani Medan road viewed from the aspect of harmony and contrast. Population in this research is billboards located along Jl. Ahmad Yani Medan. To complete the necessary data in this study, the researchers conducted data collection through observation and also the collection of related literature which became the main instrument in collecting primary data. This study is descriptive in which the data obtained in the field is collected and then analyzed, and the results described gradually in the form of writing. This study found that the influence of the existence of billboards along the road Ahmad Yani Medan has not fulfilled the aesthetic aspects in harmony and contrast.
\end{abstract}

Keywords : signage, aesthetic, visual, corridor

\begin{abstract}
Abstrak
Signage merupakan salah satu unsur pembentuk wajah kota, dengan pertimbangan begitu banyaknya jenis-jenis signage,maka dalam penelitian ini pembahasan dibatasi pada satu jenis signage saja, yaitu papan reklame.Keberagaman papan reklame yang ada sesungguhnya akan bisa berpotensi sebagai penarik bagi pengamat bila direncanakan dengan baik. Namun sebaliknya bila kehadiran papan reklame tidak diatur dengan baik dan sesuai dengan fungsinya maka tidak mustahil suasana yang diharapkan dapat berubah menjadi suasana yang tidak menyenangkan dan merusak nilai estetika visual pada kawasan ini.Dalam aspek estetika terdapat aspek harmoni dan kontras yang secara teori mendukung keberhasilan desain ruang publik dari segi estetika yang baik agar menghindari kemonotonan, dan memiliki daya tarik yang berkualitas.Permasalahan dalam penelitian ini bagaimana pengaruh papan reklame terhadap estetika visual pada jalan ahmad yani medan yang ditinjau dari aspek harmoni dan kontras. Populasi dalam penelitian ini adalah papan reklame yang berada disepanjang jl. Ahmad Yani Medan. Untuk melengkapi data-data yang diperlukan dalam penelitian ini, peneliti melakukan pengumpulan data melalui observasi dan juga pengumpulan literatur terkait yang menjadi instrument utama dalam mengumpulkan data primer.Penelitian ini bersifat deskriptif dimana data-data yang diperoleh dilapangan dikumpulkan kemudian dianalisa dan hasilnya dideskripsikan secara bertahap dalam bentuk tulisan.Penelitian ini menemukan bahwa pengaruh keberadaaan papan reklame disepanjang jalan Ahmad Yani Medan belum memenuhi aspek estetika secara harmoni dan kontras.
\end{abstract}

Kata Kunci:signage,estetika,visual,koridor 


\section{Pendahuluan}

Signage merupakan salah satu unsur pembentuk wajah visualisasi kota, dengan pertimbangan begitu banyaknya jenis-jenis signage,maka dalam penelitian ini pembahasan dibatasi pada satu jenis signage saja, yaitu papan reklame.Keberagaman papan reklame yang ada sesungguhnya akan bisa berpotensi sebagai penarik bagi pengamat bila direncanakan dengan baik. Namun sebaliknya bila kehadiran papan reklame tidak diatur dengan baik dan sesuai dengan fungsinya maka tidak mustahil suasana yang diharapkan dapat berubah menjadi suasana yang tidak menyenangkan dan merusak nilai estetika visual.

Keberadaan papan reklame yang terdapat di salah satu kawasan kota medan yang berada di Jl. Ahmad Yani berdiri dengan berbagai bentuk, dimensi, penempatan, warna, dan berbagai kriteria lainnya yang beraneka ragam tanpa memperhatikan keselarasan terhadap lingkungan sekitarnya. Dalam hal ini dirasa perlu untuk mengetahui dan mempelajari pengaruh signage/papan reklame yang terdapat di jalan ahmad yani medan terhadap estetika visual yang ditinjau dari aspek harmoni dan kontras terhadap koridor yang berada di sepanjang jalan ahmad yani medan. Sasaran dari penelitian ini adalah identifikasi estetika visual koridor dan untuk memberikan usulan papan reklame berdasarkan aspek estetika visual yang ditinjau dari aspek harmoni dan kontras.

Dalam penelitian ini juga memberikan masukan bagi ilmu pengetahuan dalam dunia arsitektur danperencanaan kota berkaitan dengan signage, serta dapat memberikan sumbangan pemikiran pada unsur-unsur penentu kebijakan dalam pertimbangan signage bukan hanya dari aspek ekonomi tetapi harus dipertimbangkan pula kondisi fisik dan visual lingkungan kota.

\section{Landasan Teori}

\section{Tinjauan signage}

Menurut Echols (1975), sign adalah tanda, sedangkan dalam arsitektur sign diartikan sebagai bentuk-bentuk informasi dan orientasi kota yang dirancang khusus sebagai bagian dari delapan elemen urban design (Shirvani,1985).

Sedangkan Rubenstein (1992) mendefinisikan bahwa signage merupakan tanda tanda visual di perkotaan yang berfungsi sebagai sarana informasi atau komunikasi secara arsitektural.

Dari pendapat di atas dapat disimpulkan pengertian signage atau penandaan ialah merupakan suatu sarana informasi visual yang bersifat arsitektural bagi masyarakat yang sedang melintas, berjalan atau berkendaraan serta dapat menciptakan image pada suatu kota.

Menurut Hamid Shirvani (1985), signage (papan reklame) yang ideal adalah :

- mampu merefleksikan karakter visual kawasan,

- mampu menjamin kemampuan dan pandangan/memiliki sudut pandang untuk dapat dilihat secara jelas,

- Bentuk yang ada sesuai dengan arsitektur bangunan di mana signage ditempatkan,

- merupakan elemen yang menyatu dengan bangunan bukan elemen tambahan, dan

- mampu menyatukan komunikasi langsung atau tidak langsung.

\section{Tinjauan aspek estetika}

Estetika (keindahan) didalam arsitektur merupakan seni visual yang mempunyai nilai-nilai yang menyenangkan mata pikiran, dan telinga, maka syarat keindahannya akan menjadi nilai-nilai yang dapat menyenangkan mata dan pikiran, atau kata lain merupakan nilai-nilai bentuk dan ekspresi yang menyenangkan (Ishar, 1993).

Ching, DK (1987) didalam satu bab pada bukunya menjelaskan bahwa salah satu factor estetika yaitu harmoni dan kontras. Harmonis dalam komposisi ruang publik kota merupakan upaya konfirmasi untuk mencapai konsistensi melalui beberapa pengulangan dari material, detail-detail tinggi rendah sebagai sentuhan dalam proses kekompakan dalam menata komposisi kota. Keberhasilan desain ruang publik dari segi estetika yang baik agar menghindari kemonotonan, dan memiliki daya tarik yang berkualitas.Kontras dalam ruang publik kota juga merupakan pemanfatan semaksimal mungkin lahan yang terbatas dengan unsur-unsur bentuk dan anti bentuk, bangunan dan ruang, jalan dan ruang terbuka publik, lansekap dan perangkat keras dan lunak. Tanpa elemen-elemen yang kontras dan kejutan-kejutan maka yang terjadi adalah pengulangan-pengulangan yang membosankan. 


\section{Tinjauan aspek visual}

Arti visual menurut Purwodarminto (1972) adalah berdasar pada penglihatan, dapat dilihat, kelihatan.Menurut Normies dalam Mulyani (1996) arti visual adalah dapat dilihat dengan indera (mata).

\section{Tinjauan aspek koridor}

Koridor (corridor) menurut Sungguh dalam Mulyani (1996) adalah gang.Sedang Purwodarminto (1997) mendefinisikan bahwa koridor adalah jalan di dalam rumah. Ditinjau dari aspek urban design, koridor adalah ruang kota sebagai sarana pergerakan linear (Budihardjo dan Sujarto, 1998).

\section{Metode Penelitian}

Metode yang digunakan dalam penelitian ini adalah metode deskriptif. Metode ini digunakan untuk memecahkan masalah yang sedang dihadapi pada situasi sekarang yang dilakukan dalam menempuh langkahlangkah pengumpulan data, klarifikasi dan analisis pengolahan dan membuat gambaran tentang suatu keadaan secara obyektif dan suatu deskriptif.

\section{Metode Pengumpulan Data}

Untuk pengumpulan data terhadap pokok bahasan tentang Pengaruh Signage Terhadap Estetika Visual Koridor Jalan menggunakan teknik study literatur dengan mencoba mengaitkan salah satu teori harmoni dan kontras yang berhubungan dengan signage, estetika visual dan koridor lalu dengan menggunakan teknik observasi dengan Melihat dan melakukan penelitian secara langsung dilapangan (objek study) dengan mengambil beberapa segmen untuk pendekatan dalam penerapan teori harmoni dan kontras. Selanjutnya teknik analisa dengan mengkaji hasil penelitian yang diperoleh dari lapangan kemudian melakukan pendekatan, penerapan teori harmoni dan kontras untuk mengambil suatu hasil dari kesimpulan penelitian.

Berdasarkan pendapat di atas yang menjadi populasi di dalam penelitian ini adalah keseluruhan papan reklame yang berada pada jalan ahmad yani medan. Signage yang menjadi populasi di dalam penelitian ini adalah seluruh jenis papan reklame yang menempel pada bangunan-bangunan pada jalan ahmad yani medan. (Tabel 1.1)

Tabel 1.1 Jumlah Jenis Populasi Jl. Ahmad Yani

\begin{tabular}{|c|c|c|c|}
\hline No & Jenis papan reklame & Timur & Barat \\
\hline 1 & Papan reklame yang menggantung & 8 Buah & 14 Buah \\
\hline 2 & Papan reklame yang menempel & 19 Buah & 29 Buah \\
\hline 3 & $\begin{array}{l}\text { Papan reklame tiang } \\
\text { Satu kaki } \\
\text { Neon box } \\
\text { Dua kaki (biasa) }\end{array}$ & $\begin{array}{l}4 \text { Buah } \\
7 \text { Buah } \\
-\end{array}$ & $\begin{array}{l}11 \text { Buah } \\
9 \text { Buah } \\
2 \text { Buah }\end{array}$ \\
\hline 4 & $\begin{array}{l}\text { Papan reklame spanduk } \\
\text { Pada kios - kios } \\
\text { Pada pohon/tiang }\end{array}$ & $\begin{array}{l}3 \text { Buah } \\
1 \text { Buah } \\
8 \text { Buah }\end{array}$ & $\begin{array}{l}- \\
2 \text { Buah } \\
4 \text { Buah }\end{array}$ \\
\hline 5 & Baliho & \multicolumn{2}{|l|}{2 Buah } \\
\hline \multicolumn{2}{|c|}{ Jumlah } & 50 Buah & 71 Buah \\
\hline
\end{tabular}

Teknik Analisis Data 
Teknik analisis data merupakan proses mengorganisasikan dan mengurutkan data ke dalam pola, kategori dan satuan uraian dasar sehingga dapat ditemukan tema dan dapat dirumuskan hipotesis kerja seperti yang didasarkan oleh data. Di dalam sebuah penelitian yang dianggap penting setelah data terkumpul adalah menganalisis data guna menguji data-data yang telah terkumpul tersebut.Dalam penelitian ini peneliti menggunakan analisis bersifat kualitatif yaitu memberikan arti dan data yang ada sesuai kenyataan yang ada di lapangan sehingga didapat kesimpulan atas masalah yang diteliti.Untuk mengetahui bagaimana pengaruh signage terhadap estetika visual pada dilihat berdasarkan perhatian, pengetahuan, dan peraturan-peraturan.

\section{Analisis}

Pembahasan pada study ini berdasarkan pada penerapan pendekatan teori-teori dan kriteria - kriteria yang telah dibahas pada bab sebelumnya, dimana dalam hal ini keberadaan papan reklame dijadikan sebagai objek untuk dikaji identifikasi pengaruh signage terhadap estetika visual koridor jalan Ahmad Yani.

Pembahasan dilakukan dengan terlebih dahulu melakukan observasi dalam pengumpulan data tentang keberadaan papan reklame pada bangunan yang berada di sepanjang jalan Ahmad Yani, kemudian menganalisa keberadaan papan reklame tersebut. Study merupakan kajian penyusunan aspek-aspek pembentuk ruang visual yang terdapat pada bangunan sebelah kiri dan sebelah kanan jl.Ahmad Yani terhadap elemen signage(Gambar 1.2)

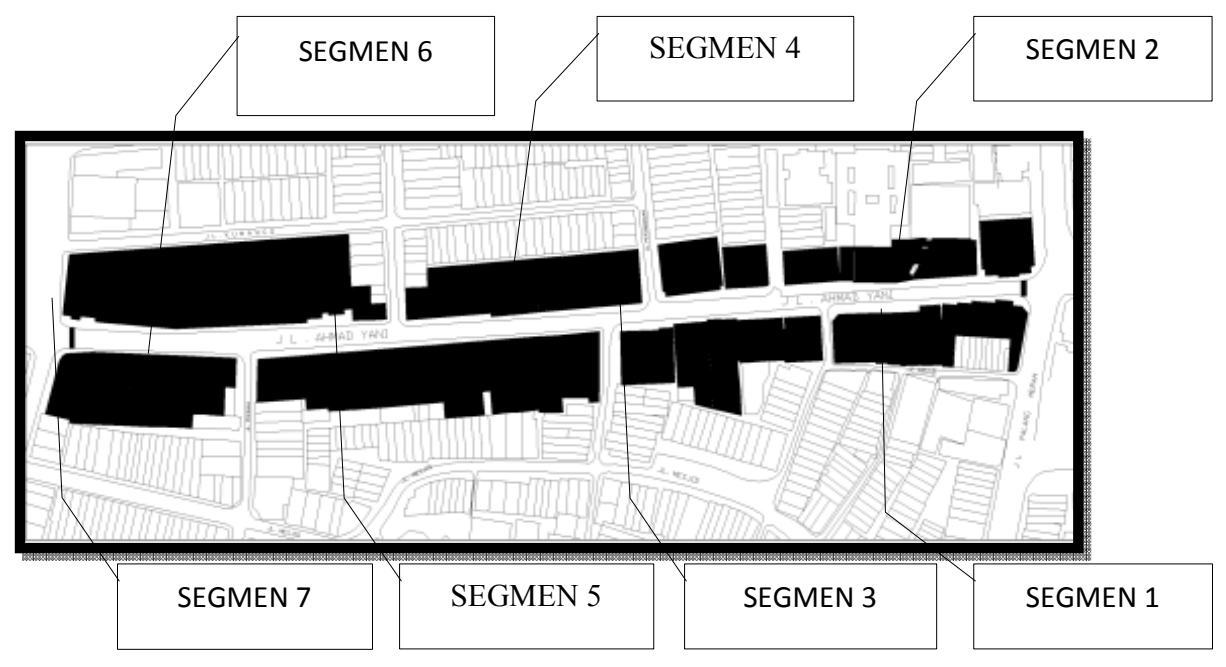

Gambar 1. Lokasi Penelitian

Sebelum analisa dilakukan maka perlu dibuat suatu kriteria penilaian dalam perancangan signage terhadap objek yang ditinjau dari beberapa teori.Kriteria penilaian dibuat berdasarkan teoriharmoni dan kontras.Kriteria penilaian inilah yang akandijadikan acuan dalam memberi penilaian terhadap analisa yang dilakukan. Untuk lebih jelasnya dapat dilihat dibawah ini :

\section{Analisa Harmoni Dan Kontras}

Warna yang kontras menyebabkan tanda lebih mudah terbaca daripada kombinasi warna yang sepadan. Kombinasi yang terbaik adalah tulisan putih dengan latar belakang hitam akan lebih besar bila dibandingkan dengan tulisan hitam dengan latar belakang putih, walaupun ukuran tanda atau huruf dan posisi yang sama. Warna juga akan mempengaruhi keterkaitan antara ukuran tulisan dengan latar belakangnya. Pemilihan warna juga harus dipertimbangkan dengan warna bangunan dan lingkungan sekitarnya. (Gambar 1.3) 


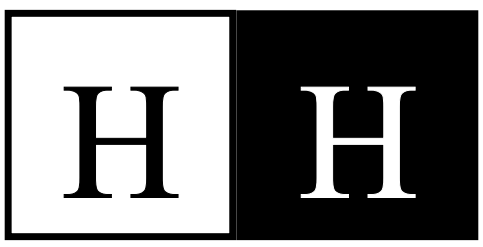

Gambar 2.Harmoni dan Kontras

Pertimbangan untuk menarik perhatian dengan pemberian cahaya (lampu) pada papan reklame juga dapat menimbulkan efek yang kontras.

Analisa dalam menentukan harmoni dan kontras dinilai dari keberhasilan desain ruang publik dari segi estetika yang baik agar menghindari kemonotonan, dan memiliki daya tarik yang berkualitas. Kontras dalam ruang publik kota juga merupakan pemanfatan semaksimal mungkin lahan yang terbatas dengan unsur-unsur bentuk dan anti bentuk, bangunan dan ruang, jalan dan ruang terbuka publik, lansekap dan perangkat keras dan lunak. Tanpa elemen-elemen yang kontras dan kejutan-kejutan maka yang terjadi adalah pengulangan-pengulangan yang membosankan.

Pembahasan terhadap hasil penelitian ini dilakukan berdasarkan sistematika pembahasan pada indikator aspek harmoni dan kontras yang telah ditentukan pada penekanan bentuk yang tidak monoton dan berkualitas baik serta kombinasi warna terbaik dengan latar belakang lebih gelap daripada tulisan utama(Tabel 1.2)

Tabel 1 Analisa Harmoni dan Kontras

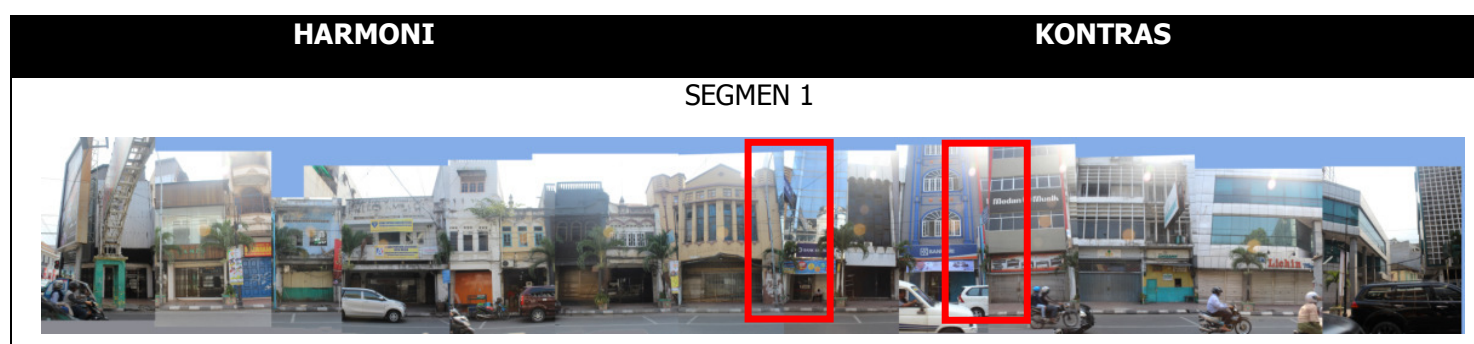

Gambar 1

Penekanan bentuk papan reklame yang tidak monoton dari tampak keseluruhan segmen 1 serta memaksimalkan lahan yang terbatas namun perletakkan di tempat yang tidak tepat. (Gambar 1)
Kombinasi yang terbaik adalah tulisan putih dengan latar belakang hitam akan lebih besar bila dibandingkan dengan tulisan hitam dengan latar belakang putih, walaupun ukuran tanda atau huruf dan posisi yang sama. dari 15 bangunan hanya 2 bangunan yang memiliki kombinasi warna yang baik seperti tampak pada papan reklame Medan Musik dan bank mestika (Gambar 1)

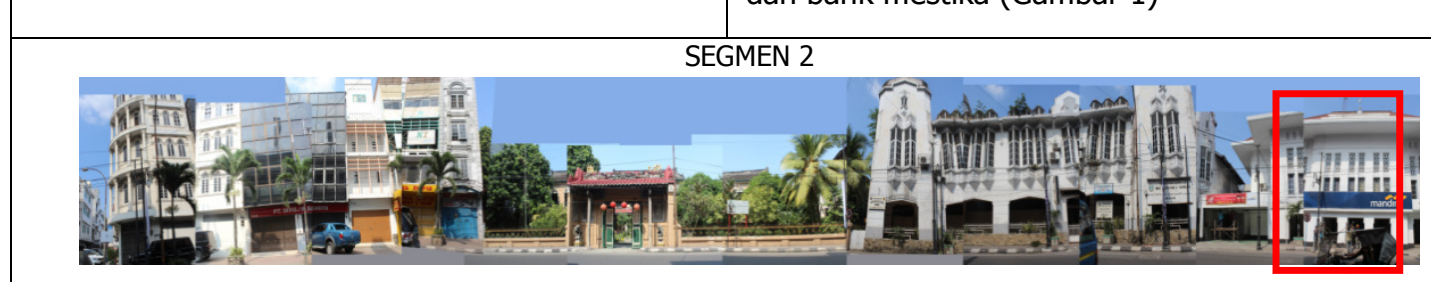

(Gambar 2)

Penekanan bentuk papan reklame monoton dari $\quad$ Kombinasi yang terbaik adalah tulisan putih dengan

tampak keseluruhan segmen ini serta latar belakang hitam akan lebih besar bila


memaksimalkan lahan yang terbatas dan perletakkan di tempat yang tepat, namun papan reklame tidak memperhatikan kococokan antara papan reklame dan bangunan sejarah (Gambar 2) dibandingkan dengan tulisan hitam dengan latar belakang putih , walaupun ukuran tanda atau huruf dan posisi yang sama. dari 14 bangunan hanya 1 bangunan yang memiliki kombinasi warna yang baik seperti tampak pada papan reklame Bank Mandiri (Gambar 1)

SEGMEN 3

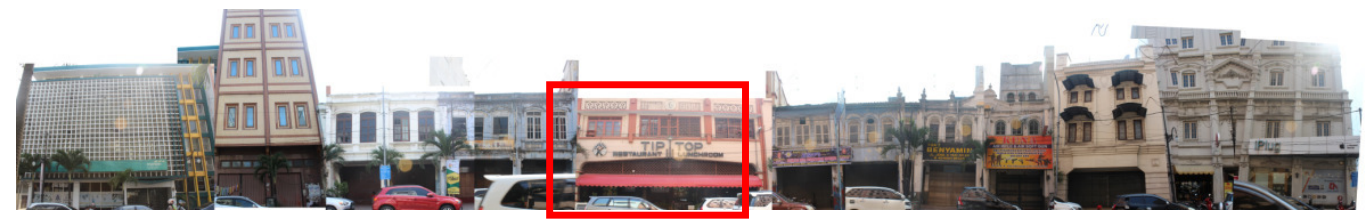

(Gambar 3)

Penekanan bentuk papan reklame tidak monoton dari tampak keseluruhan segmen ini serta memaksimalkan lahan yang terbatas dan perletakkan di tempat yang tepat,papan reklame pada segmen ini memperhatikan kococokan antara papan reklame dan bangunan sejarah.tampak pada bangunan bank syariah mandiri,restaurant tip top, dan took Iplug. (Gambar 3)
Kombinasi yang terbaik adalah tulisan putih dengan latar belakang hitam akan lebih besar bila dibandingkan dengan tulisan hitam dengan latar belakang putih, walaupun ukuran tanda atau huruf dan posisi yang sama. dari 12 bangunan hanya 1 bangunan yang memiliki kombinasi warna yang baik seperti tampak pada papan reklame restaurant tip top (Gambar 3)

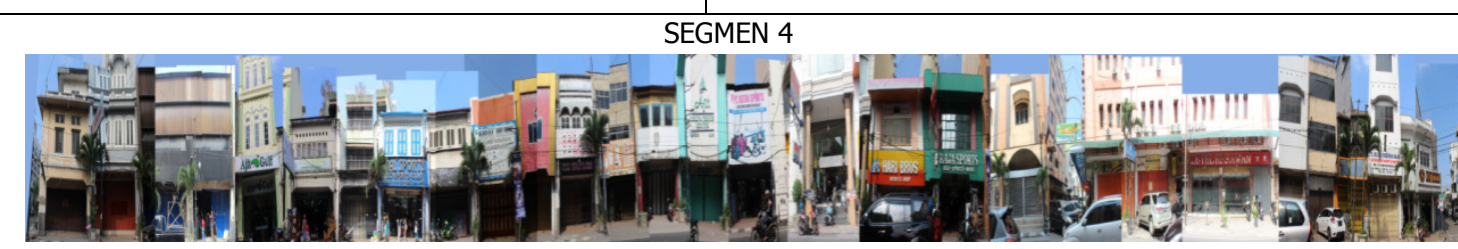

(Gambar 4)

Penekanan bentuk papan reklame tidak monoton dari tampak keseluruhan segmen ini serta memaksimalkan lahan yang terbatas dan perletakkan di tempat yang tepat,papan reklame pada segmen ini memperhatikan kococokan antara papan reklame dan fungsi bangunan (Gambar 4)
Kombinasi yang terbaik adalah tulisan putih dengan latar belakang hitam akan lebih besar bila dibandingkan dengan tulisan hitam dengan latar belakang putih, walaupun ukuran tanda atau huruf dan posisi yang sama. dari 27 bangunan tidak satupun bangunan yang memiliki kombinasi warna yang baik pada segmen ini (Gambar 4)

SEGMEN 5

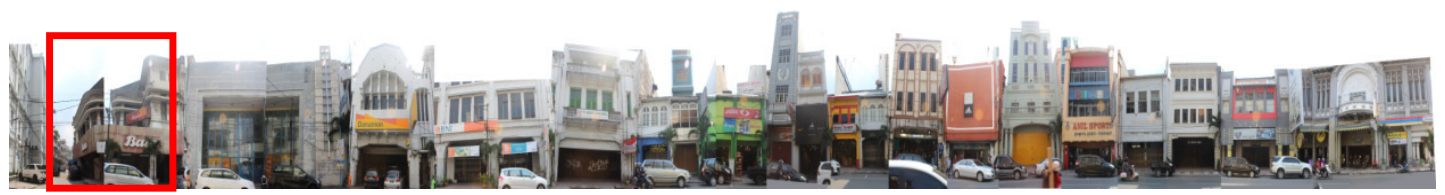

(Gambar 5)

Penekanan bentuk papan reklame tidak monoton dari tampak keseluruhan segmen ini serta memaksimalkan lahan yang terbatas dan perletakkan di tempat yang tepat,papan reklame
Kombinasi yang terbaik adalah tulisan putih dengan latar belakang hitam akan lebih besar bila dibandingkan dengan tulisan hitam dengan latar belakang putih , walaupun ukuran tanda atau huruf 


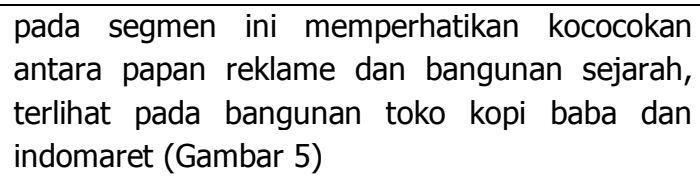

dan posisi yang sama. dari 21 bangunan hanya 1 bangunan yang memiliki kombinasi warna yang baik seperti tampak pada papan reklame bata (Gambar 5)

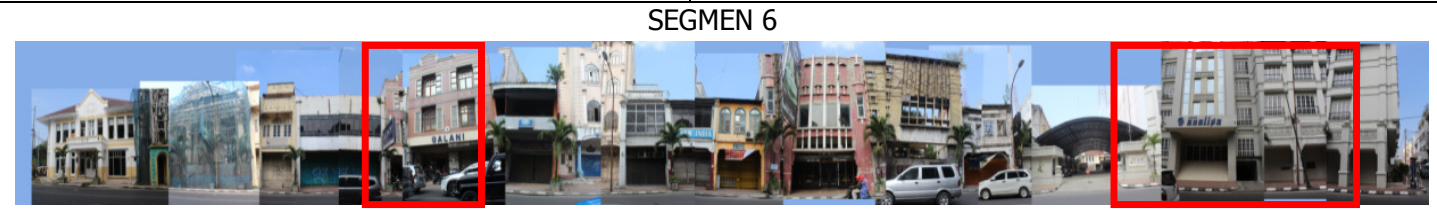

Gambar 6

Penekanan bentuk papan reklame tidak monoton dari tampak keseluruhan segmen ini serta memaksimalkan lahan yang terbatas dan perletakkan di tempat yang tepat,papan reklame pada segmen ini memperhatikan kococokan antara papan reklame dan bangunan sejarah.tampak pada bangunan analisa (Gambar 6)
Kombinasi yang terbaik adalah tulisan putih dengan latar belakang hitam akan lebih besar bila dibandingkan dengan tulisan hitam dengan latar belakang putih , walaupun ukuran tanda atau huruf dan posisi yang sama. dari 13 bangunan hanya 2 bangunan yang memiliki kombinasi warna yang baik seperti tampak pada papan bangunan analisa dan toko galani(Gambar 6)

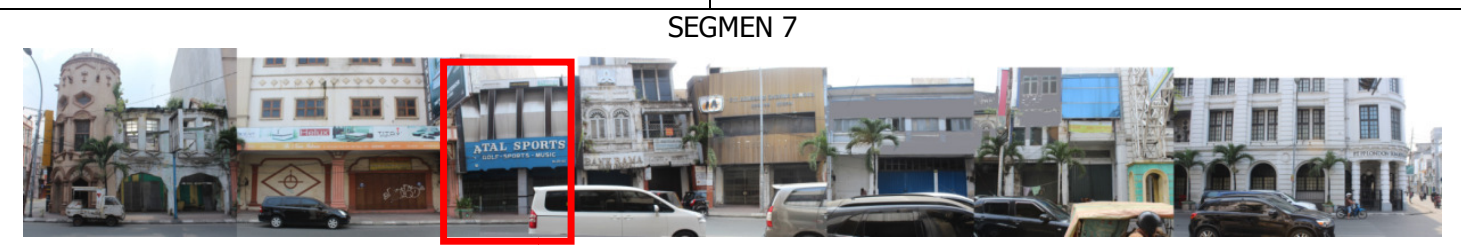

Gambar 7

Penekanan bentuk papan reklame tidak monoton dari tampak keseluruhan segmen ini serta memaksimalkan lahan yang terbatas dan perletakkan di tempat yang tepat,papan reklame pada segmen ini tidak memperhatikan kococokan antara papan reklame dan bangunan sejarah.tampak pada bangunan londsum dan papan reklame persimpangan jalan masjid (Gambar 7)
Kombinasi yang terbaik adalah tulisan putih dengan latar belakang hitam akan lebih besar bila dibandingkan dengan tulisan hitam dengan latar belakang putih, walaupun ukuran tanda atau huruf dan posisi yang sama. dari 12 bangunan hanya 1 bangunan yang memiliki kombinasi warna yang baik seperti tampak pada papan reklame atal sport (Gambar 7)

\section{Kesimpulan dan Saran}

Penelitian mengenai harmoni dan kontras mengenai papan reklame terhadap estetika visual yang berada disepanjang jalan Ahmad Yani dengan jumlah 121 papan reklame dari 114 bangunan menyimpulkan bahwa keberadaaan papan reklame belum memenuhi aspek estetika secara harmoni dan kontras walaupun telah memaksimalkan lahan yang terbatas namun Penekanan bentuk papan reklame yang cukup monoton dan perletakkannya di tempat yang belum tepat. Dari keseluruhan papan reklame disepanjang jalan ahmad yani hanya 8 bangunan yang memiliki kombinasi papan reklame warna yang baik seperti tampak pada papan reklame Medan Musik dan Bank Mestika, Bank Mandiri, Restaurant Tip Top, toko Bata, bangunan Harian Analisa dan toko Galani dan toko Atal Sport.

\section{Saran}


Dalam perancanganpapan reklame di sepanjang jalan Ahmad Yani dalam aspek Harmoni dan Kontras baiknya memperhatikan penekanan bentuk yang tidak monoton serta mengkombinasikan warna yang baik agar mendapatkan harmoni dan kontras yang berkualitas baik.

\section{Daftar Pustaka}

Adityan, Novri, 2008, Penerapan Signage dalam Mall, Skripsi Departemen Arsitektur Fakultas Teknik Universitas Indonesia

Catanese, Anthony; Snyder, James, 1984, Pengantar Perancangan Kota (Introduction to urban Planning ), Penerbit Erlangga

Ching, Francis D.K, 1993, Arsitektur Bentuk, Ruang dan Tatanan, Penerbit Erlangga

Ishar, H,K, 1992, Pedoman Umum Merancang Bangunan, Penerbit PT Gramedia, Jakarta

Murtomo, B.Adji, 2007, Penataan Papan Reklame Pada Penggal Hayam Wuruk Semarang, Enclosure Jurnal Ilmiah Perancangan Kota dan Permukiman Volume 6 No.1

Sudarwani, Maria, 2010, Pengaruh Signage Pada Bangunan-Bangunan Komersil Terhadap Estetika Visual koridor, Thesis Universitas Diponegoro.

Http://PotretKotaMedanTempoDuludanKini/Tipsiana.htmldibuka pada 29 juli 2015 